\title{
MODIFICATION OF n-SI CHARACTERISTICS BY ANNEALING AND COOLING AT DIFFERENT RATES
}

\author{
SUBHI K. SALIH ${ }^{a}$, HIKMAT S. HILAL ${ }^{a, *}$, IYAD A. SA'DEDDIN ${ }^{a}$, \\ ELISABETH SELLIER ${ }^{b}$ and GUY CAMPET ${ }^{b}$ \\ ${ }^{a}$ College of Sciences, An-Najah N. University, P.O. Box 7, West Bank, Palestine; \\ bInstitut de Chimie de la Matiere Condensee de Bordeaux du CNRS, Chateau Brivazac, \\ avenue du Dr. A. Schweitzer, 33608 Pessac, France
}

(Received 30 December 2002; In final form 21 March 2003)

\begin{abstract}
The effect of annealing of the $\mathrm{n}$-Si semiconductor on its characteristics in photoelectrochemical systems has been investigated. The annealing improved the dark current density vs. potential plots. The surface was improved by annealing, as manifested by SEM results. The effect of the cooling rate on preheated $n$-Si wafers was also investigated. It was found that the slowly cooled electrodes gave better dark current density vs. potential plots, for samples annealed at lower than $550^{\circ} \mathrm{C}$. For samples annealed at higher temperatures, quenching gave better dark-current density vs. potential plots. SEM measurements showed parallel results to these findings. Enhanced surface textures were observed for slowly cooled wafers from temperatures below $550^{\circ} \mathrm{C}$. Samples quenched from temperatures above $550^{\circ} \mathrm{C}$ showed better surfaces than slowly cooled counterparts.
\end{abstract}

Keywords: $n$-Si; A nnealing; Cooling rate; J-V plots; SEM

\section{INTRODUCTION}

Semiconductor (SC) surface enhancement can be obtained by annealing the wafer. A nnealing of SC wafers leads to enhancement of their efficiency in the PEC solar cells [1].

Crystal imperfection is a common feature associated with el evated heating. In metallic conductors, the heat imperfection causes expansions and conductivity lowering behavior in the crystal. The rate of cooling of heated metal crystals affects the crystal properties. Quenching of heated aluminum rods prevents contraction to their original length [2]. $M$ etastable spheres in the heated crystal will be deprived of any energy that is needed for return. A lternatively, slow cooling would allow the return of metastable spheres to their original positions. Therefore, it is assumed that slow cooling improves crystallinity.

Literature shows how annealing SC wafers improves their crystallinity [1,3-8]. Slow cooling of annealed SC wafers is also reported to enhance crystallinity [9-13]. It has also been found that the dark current could be greatly reduced through rapid thermal annealing of porous silicon SC [14].

\footnotetext{
* Corresponding author. E-mail: hikmathilal@yahoo.com
} 
By improving crystallinity, the SC wafer treatment should improve its characteristics at the solid/liquid interface in PEC. If the annealed SC is slowly cooled, it would retain its original order, with fewer imperfections. If quenched, the annealed crystal would become more imperfect.

In our efforts to enhance the efficiency of light to electricity onto SC surfaces, we hereby present a convenient method to enhance the band-edge and surface structures of monocrystalline commercially made SCs for the purpose of enhancing their PEC characteristics.

\section{EXPERIMENTAL}

\subsection{M aterials}

$\mathrm{LiClO}_{4}, \mathrm{~K}_{3} \mathrm{Fe}(\mathrm{CN})_{6}$ and $\mathrm{K}_{4} \mathrm{Fe}(\mathrm{CN})_{6}$ were purchased from Aldrich. All organic solvents (methanol, dichloromethane, DM F) were obtained from Riedel-D eH aën in a pure form.

\subsection{Equipment}

J-V plots were measured using a computerized PAR 263A potentiostat. A three-electrode one-compartment photoelectrochemical cell, equipped with a platinum counter electrode, SCE reference, was used. $\mathrm{Fe}(\mathrm{CN})_{6}^{3-/ 4-}\left(0.05 \mathrm{M} \mathrm{K}{ }_{3} \mathrm{Fe}(\mathrm{CN})_{6}, 0.05 \mathrm{M} \mathrm{K}_{4} \mathrm{Fe}(\mathrm{CN})_{6}\right)$ was used as a redox couple in distilled water with ( $\mathrm{pH} 6.5)$, and $\mathrm{LiClO}_{4}$ as a supporting electrolyte. $\mathrm{N}_{2}$ was bubbled through the solution at least 5 min before each experiment, and was kept to bubble above the solution during the experiment to minimize contamination with air. SEM measurements were conducted using a JEOL $2000 \mathrm{FX}$ electron microscope.

\subsection{Wafer Annealing}

A nnealing was conducted using a thermostated horizontal tube furnace. A closed clay crucible, with the SC wafer inside, was inserted in a long stainless steel cylinder and the assembly was placed inside the furnace under an $\mathrm{N}_{2}$ stream. The temperature was set and kept at the desired level $\left(400,500,600\right.$ or $\left.700^{\circ} \mathrm{C}\right)$ for an extra $20 \mathrm{~min}$. Cooling was then started. Quenching was conducted by dipping the stainless steel cylinder into enough amounts of water. The room temperature was reached within one minute. Slow cooling was conducted in a stepwise process. In each step, the temperature setting was lowered by 50 degrees and allowed to settle for $20 \mathrm{~min}$. Depending on the starting annealing temperature, a total of 8-12 hours was needed for slow cooling to occur.

\subsection{Electrode Fabrication}

M ono-crystalline $\langle 111\rangle$ single-surface polished n-Si wafers, with 300-500 ohm-cm resistivity, were used. The thickness was $\sim 300 \mu \mathrm{m}$. The $n-S i$ electrodes were fabricated as follows: the wafer was cut into small pieces $\left(\sim 0.1 \mathrm{~cm}^{2}\right)$. The pieces were then annealed at the desired temperatures. After cooling to room temperature, the piece was mounted to a copper plate (welded to a copper wire), using Ga-In eutectic on both the copper plate and the semiconductor unpolished (back) face [15]. The copper wire was Teflon-insulated. The exposed $\mathrm{Cu}$ and Ga-In eutectic with semiconductor edges of the electrode were then sealed with epoxy cement, leaving only the electrode polished mirror face exposed to the solution. 
The electrodes were left to dry for at least 24 hours at room temperature under nitrogen, before rinsing with methanol and drying with a slow stream of $\mathrm{N}_{2}$.

All electrodes were etched, prior to use, with HF solution ( $49 \%$ by mass), as shown earlier [16]. The electrode was immersed in the HF solution for about $20 \mathrm{~s}$, rinsed with distilled water, and then washed with methanol. The above process was repeated three times to remove undesirable oxides and obtain a shiny mirror surface.

\section{RESULTS}

$\mathrm{n}$-Si wafers were treated by heating and cooling. The wafers were heated to a desired temperature $\left(400^{\circ} \mathrm{C}, 500^{\circ} \mathrm{C}, 600^{\circ} \mathrm{C}, 700^{\circ} \mathrm{C}\right.$, or $\left.800^{\circ} \mathrm{C}\right)$. Cooling of heated wafers to room temperature $\left(25^{\circ} \mathrm{C}\right)$ was done using two different methods, quenching and slow cooling. Dark J-V plots and SEM measurements of surface probed the effect of treatment on the SC characteristics.

\subsection{Dark J -V Plot Enhancement of n-Si Samples}

\subsubsection{Annealing Effect on $\mathrm{n}-\mathrm{Si}$ Characteristics}

The $\mathrm{n}$-Si samples were heated, to different temperatures, and then cooled (slowly or by quenching) to room temperatures. The heated samples showed better dark J -V plots than the untreated samples.

Figure 1 shows better dark J - V plots for quenched samples than for the untreated counterparts. The quenched samples, from heating temperatures of $600^{\circ} \mathrm{C}$ and $700{ }^{\circ} \mathrm{C}$, showed the best J - $V$ plots. In fact, we will observe that the best dark J - V plots was obtained with the highest annealing temperature. Better dark J-V plots for slowly cooled samples were also obtained, compared to untreated ones, as shown in Figure 2, but in this case the plot quality was independent of annealing temperature.

\subsubsection{Effect of Rate of Cooling from Temperatures Below $550^{\circ} \mathrm{C}$}

Figures 3 and 4 show dark J -V plots measured for slowly cooled and quenched samples from $400^{\circ} \mathrm{C}$ and $500{ }^{\circ} \mathrm{C}$, respectively. We notice that slowly cooled samples showed better dark $\mathrm{J}-\mathrm{V}$ plots than quenched counterparts. In fact we established that such behavior occurs provided that the heating temperature does not exceed $550^{\circ} \mathrm{C}$.

\subsubsection{E ffect of Rate of Cooling from Temperatures A bove $550^{\circ} \mathrm{C}$}

Contrary to the lower temperature range, the quenched samples showed better dark J-V plots than the slowly cooled ones (Figs. 5 and 6).

\subsection{SEM Results}

The surface quality is a key factor in SC performance in photoelectrochemical (PEC) systems. SEM is helpful to study the surface quality. 


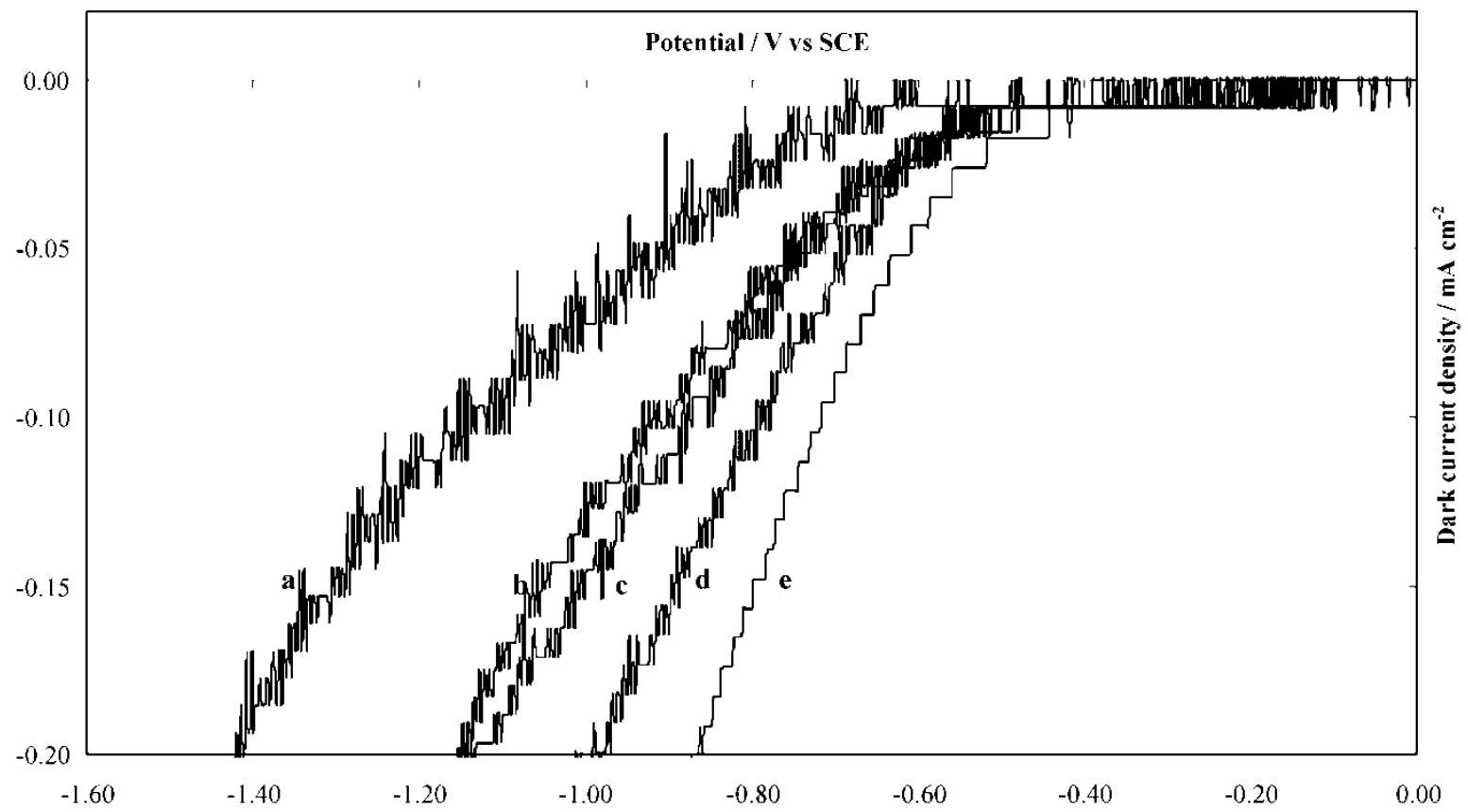

FIGURE 1 Dark J-V plots for (a) unheated n-Si. Quenched n-Si samples from (b) $400^{\circ} \mathrm{C}$, (c) $500^{\circ} \mathrm{C}$, (d) $600^{\circ} \mathrm{C}$, and (e) $700^{\circ} \mathrm{C}$. All J-V measurements were conducted in water $/ \mathrm{LiClO}_{4} / \mathrm{K}_{4}\left[\mathrm{Fe}(\mathrm{CN})_{6}\right] / \mathrm{K}_{3}\left[\mathrm{Fe}(\mathrm{CN})_{6}\right]$ at $25^{\circ} \mathrm{C}$ 


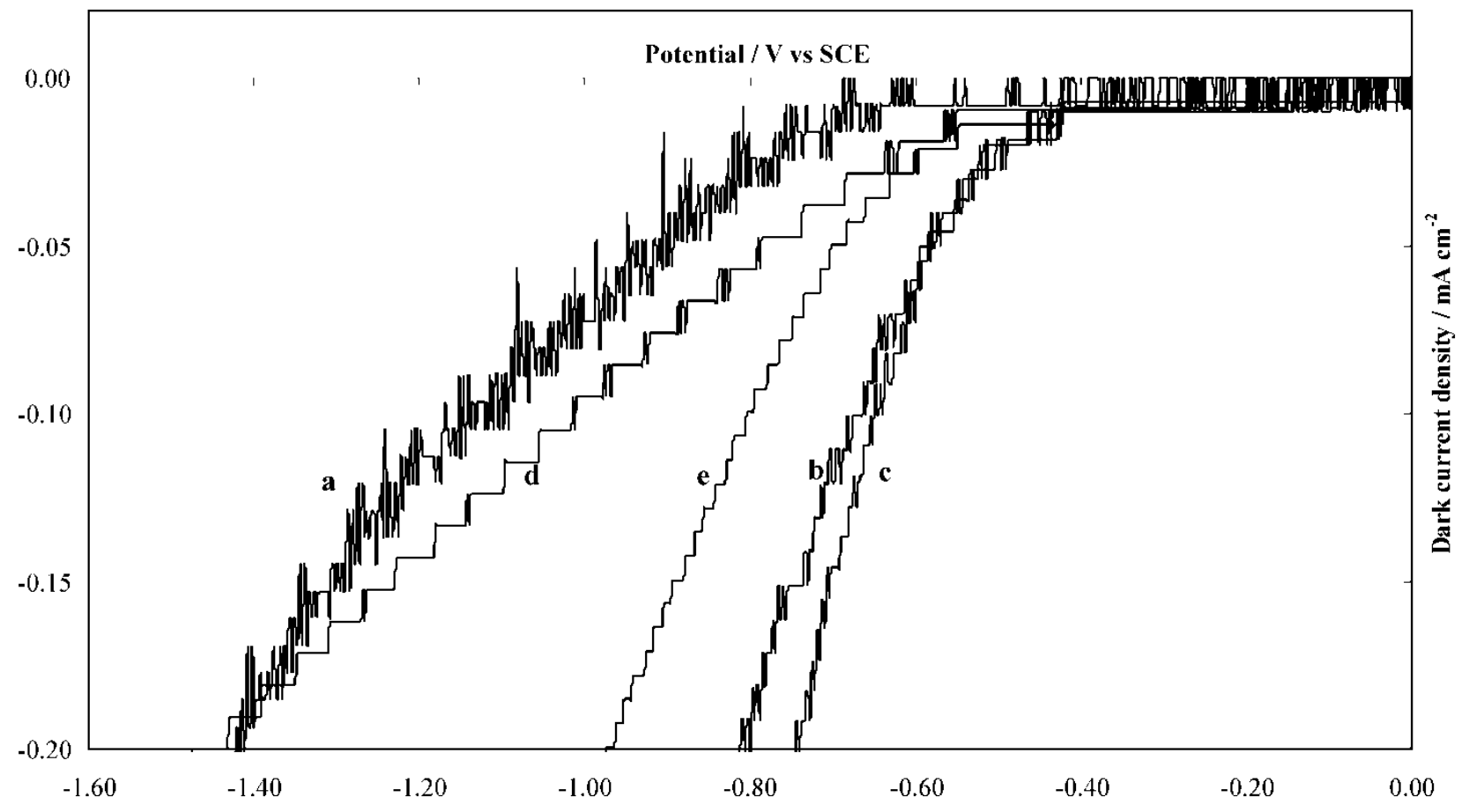

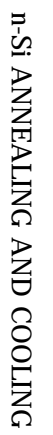

FIGURE 2 Dark J-V plots for (a) unheated n-Si. Slowly cooled n-Si samples from (b) $400^{\circ} \mathrm{C}$, (c) $500^{\circ} \mathrm{C}$, (d) $600^{\circ} \mathrm{C}$, and (e) $700^{\circ} \mathrm{C}$. All J-V measurements were conducted in water $/ \mathrm{LiClO} \mathrm{O}_{4} / \mathrm{K}_{4}\left[\mathrm{Fe}(\mathrm{CN})_{6}\right] / \mathrm{K}_{3}\left[\mathrm{Fe}(\mathrm{CN})_{6}\right]$ at $25^{\circ} \mathrm{C}$. 


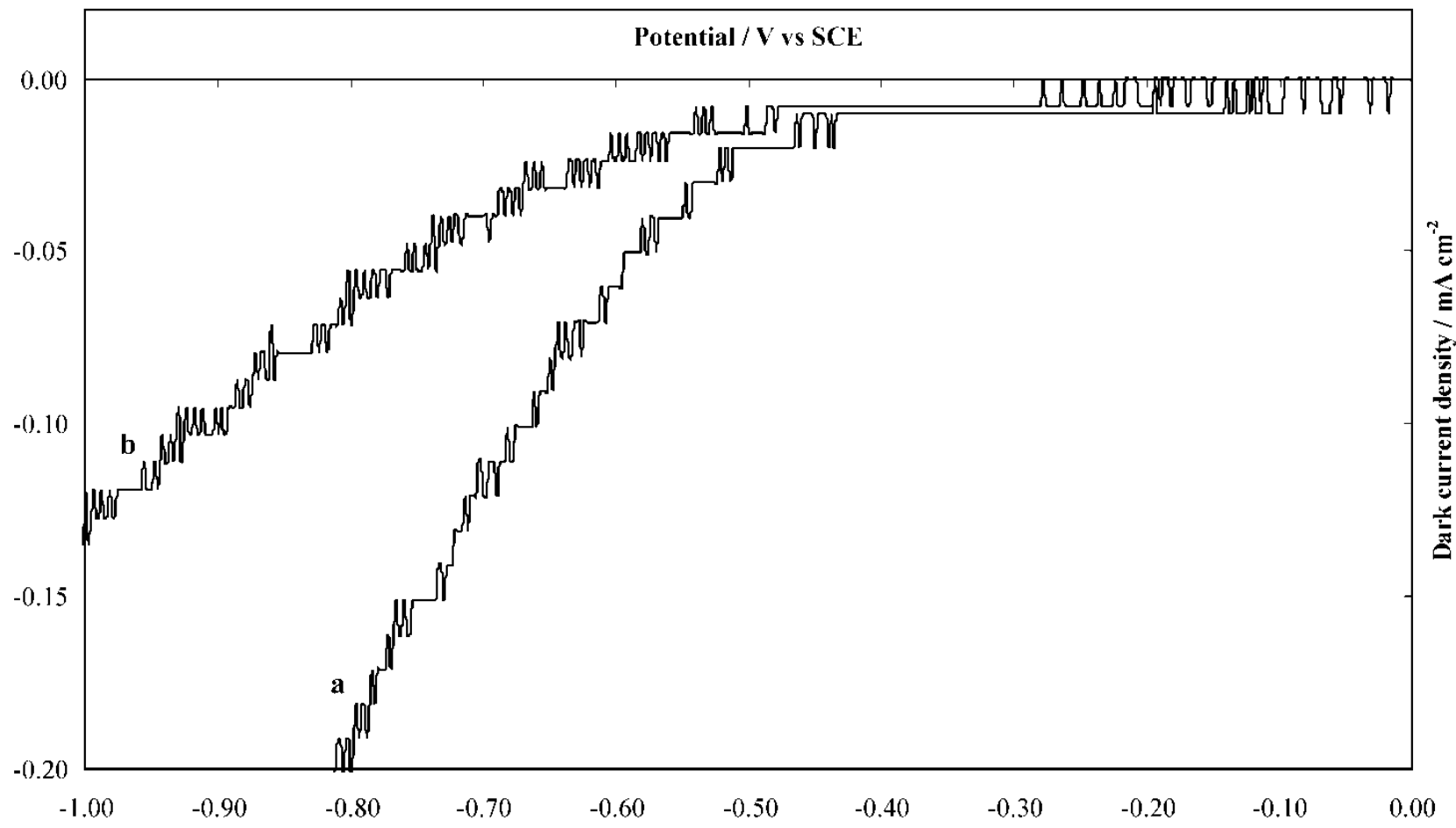

FIGURE 3 Dark J-V plots of (a) slowly cooled and (b) quenched n-Si samples from $400^{\circ} \mathrm{C}$. All J $-\mathrm{V}$ measurements were conducted in water $/ \mathrm{LiClO} / / \mathrm{K}_{4}\left[\mathrm{Fe}(\mathrm{CN})_{6}\right] / \mathrm{K}_{3}\left[\mathrm{Fe}(\mathrm{CN})_{6}\right]$ at $25^{\circ} \mathrm{C}$. 


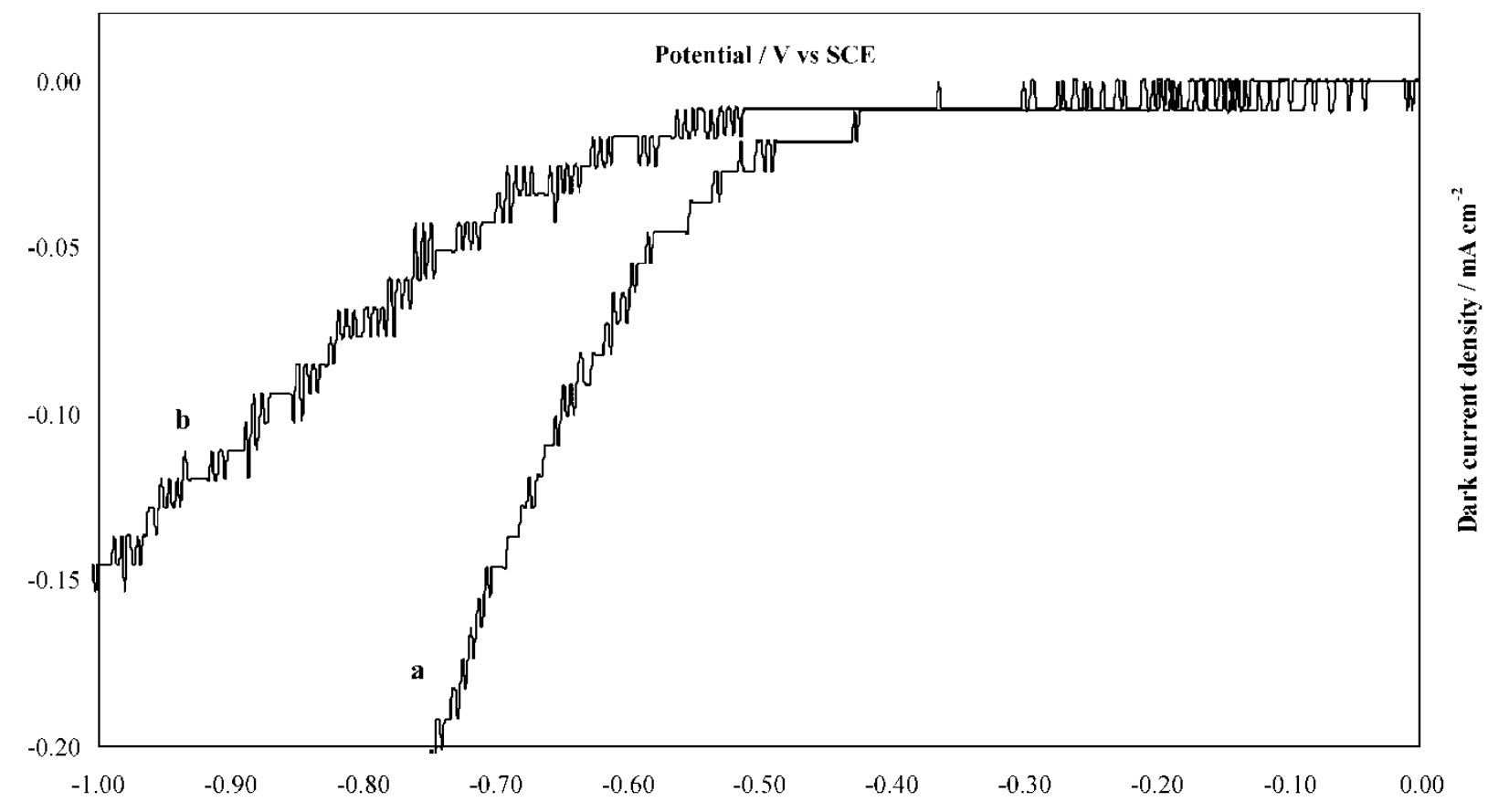

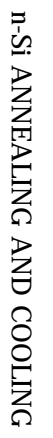

FIGURE 4 Dark J-V plots of (a) slowly cooled and (b) quenched n-Si from $500^{\circ} \mathrm{C}$. All J-V measurements were conducted in water $/ \mathrm{LiClO}{ }_{4} / \mathrm{K}_{4}\left[\mathrm{Fe}(\mathrm{CN})_{6}\right] / \mathrm{K}_{3}\left[\mathrm{Fe}(\mathrm{CN})_{6}\right]$ at $25^{\circ} \mathrm{C}$. 


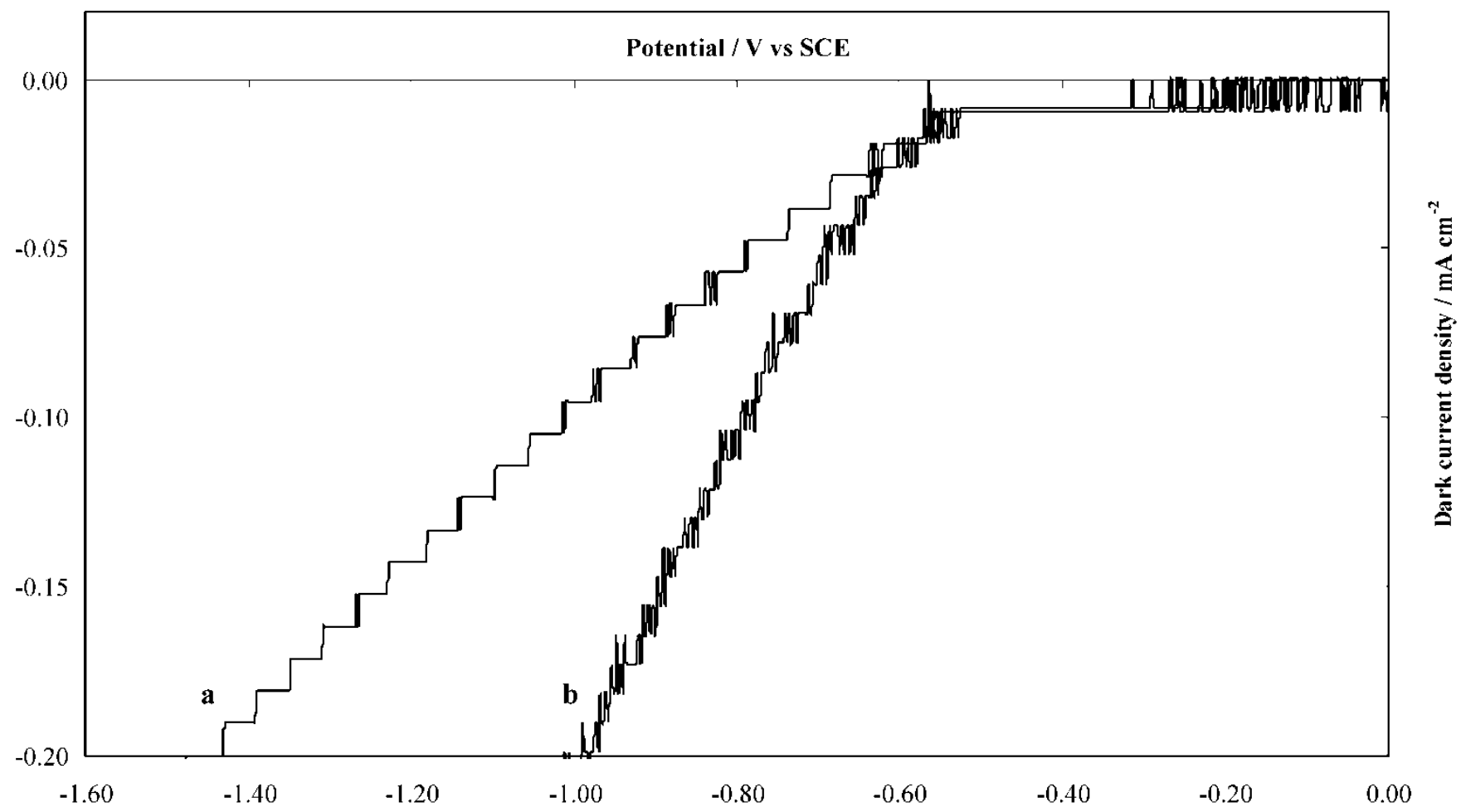

FIGURE 5 Dark J-V plots of (a) slowly cooled and (b) quenched n-Si from $600^{\circ} \mathrm{C}$. All J-V measurements were conducted in water $/ \mathrm{LiClO}{ }_{4} / \mathrm{K}_{4}\left[\mathrm{Fe}(\mathrm{CN})_{6}\right] / \mathrm{K}_{3}\left[\mathrm{Fe}(\mathrm{CN})_{6}\right]$ at $25^{\circ} \mathrm{C}$. 


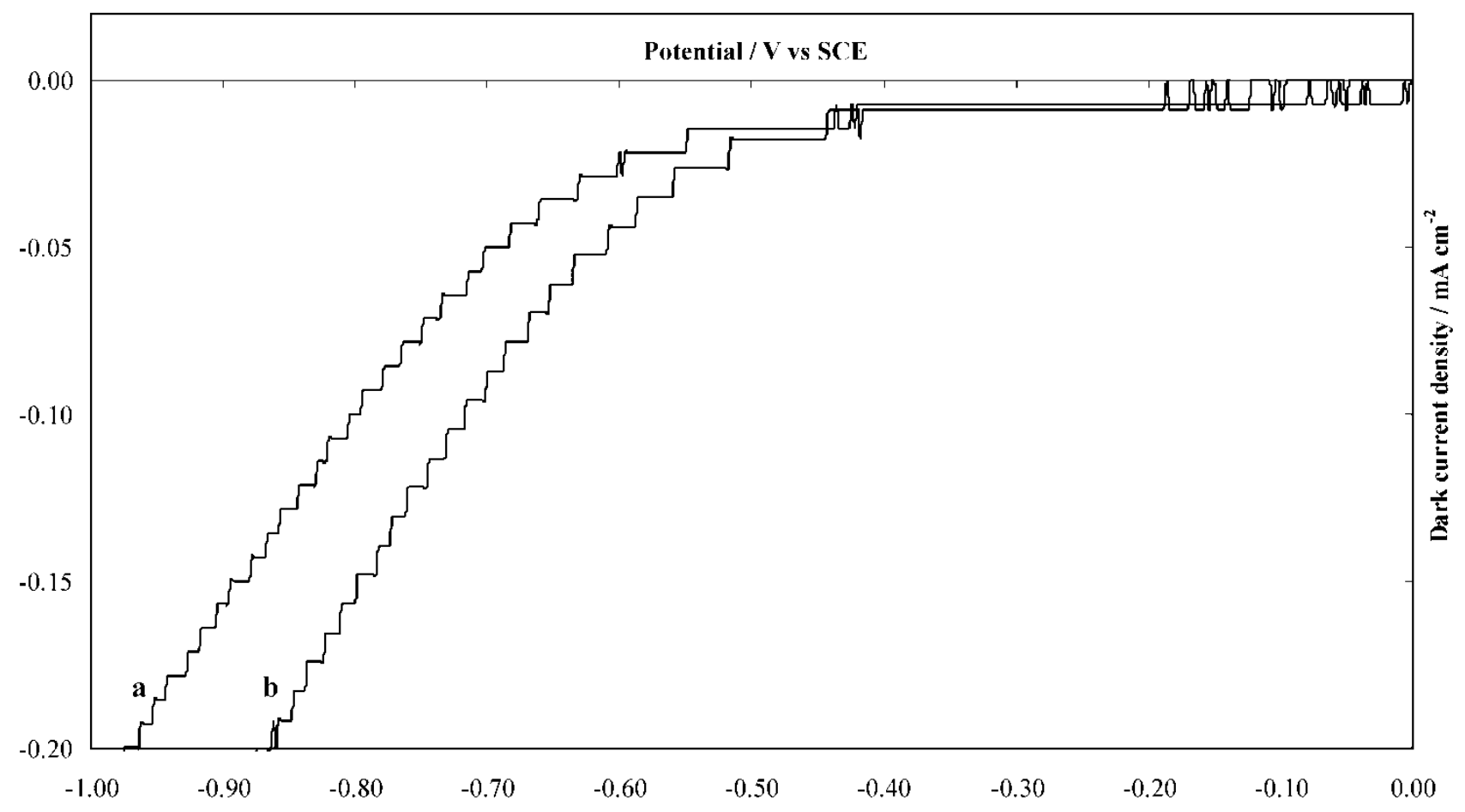

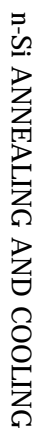

FIGURE 6 Dark J-V plots of (a) slowly cooled and (b) quenched n-Si from $700^{\circ} \mathrm{C}$. All J $-\mathrm{V}$ measurements were conducted in water $/ \mathrm{LiClO} \mathrm{O}_{4} / \mathrm{K}_{4}\left[\mathrm{Fe}(\mathrm{CN})_{6}\right] / \mathrm{K}_{3}\left[\mathrm{Fe}(\mathrm{CN})_{6}\right]$ at $25^{\circ} \mathrm{C}$. 


\subsubsection{Effect of SC Heating on SEM Results}

SEM results for Si samples, annealed and then cooled to room temperature, showed better quality surfaces than untreated counterparts. This was evident in both quenching and slow cooling processes.

Figure 7 shows SEM results for untreated $n$-Si surface. The surface has many islands and aggregates. In the case of quenched samples, better SEM surface quality is obtained. SEM indicates that $\mathrm{n}$-Si surfaces, quenched from $400{ }^{\circ} \mathrm{C}$, are rough, but to a lesser extent than untreated ones (Fig. 8). Heating to $600{ }^{\circ} \mathrm{C}$ reduces the surface roughness, as observed for the quenched $\mathrm{n}$-Si surface (Fig. 9). The n-Si wafer, quenched from $700^{\circ} \mathrm{C}$, (Fig. 10), shows a clearer surface with no islands, aggregates, or cracks. SEM thus indicates that for all quenched surfaces, higher heating temperatures give better $n$-Si surfaces.

SEM results show better surfaces for slowly cooled $n$-Si samples, than for the untreated samples. For the $n-S i$ sample, slowly cooled from $400{ }^{\circ} \mathrm{C}$, SEM shows only one small aggregate on the surface, indicating a high surface quality (Fig. 11). SEM shows a rough surface

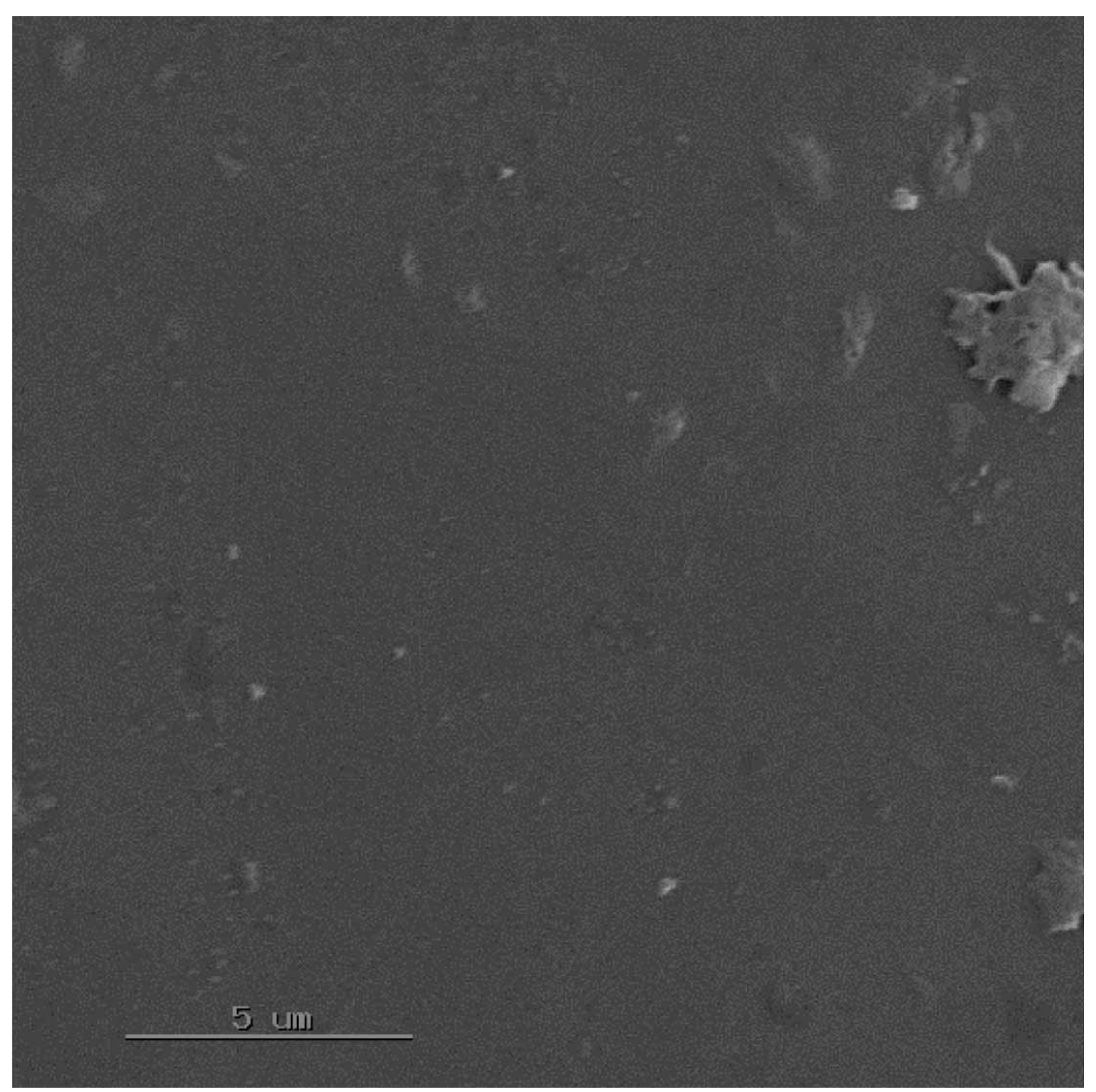

FIGURE 7 SEM image for untreated sample of $n-S i$ with scale of $5 \mu \mathrm{m}$. 


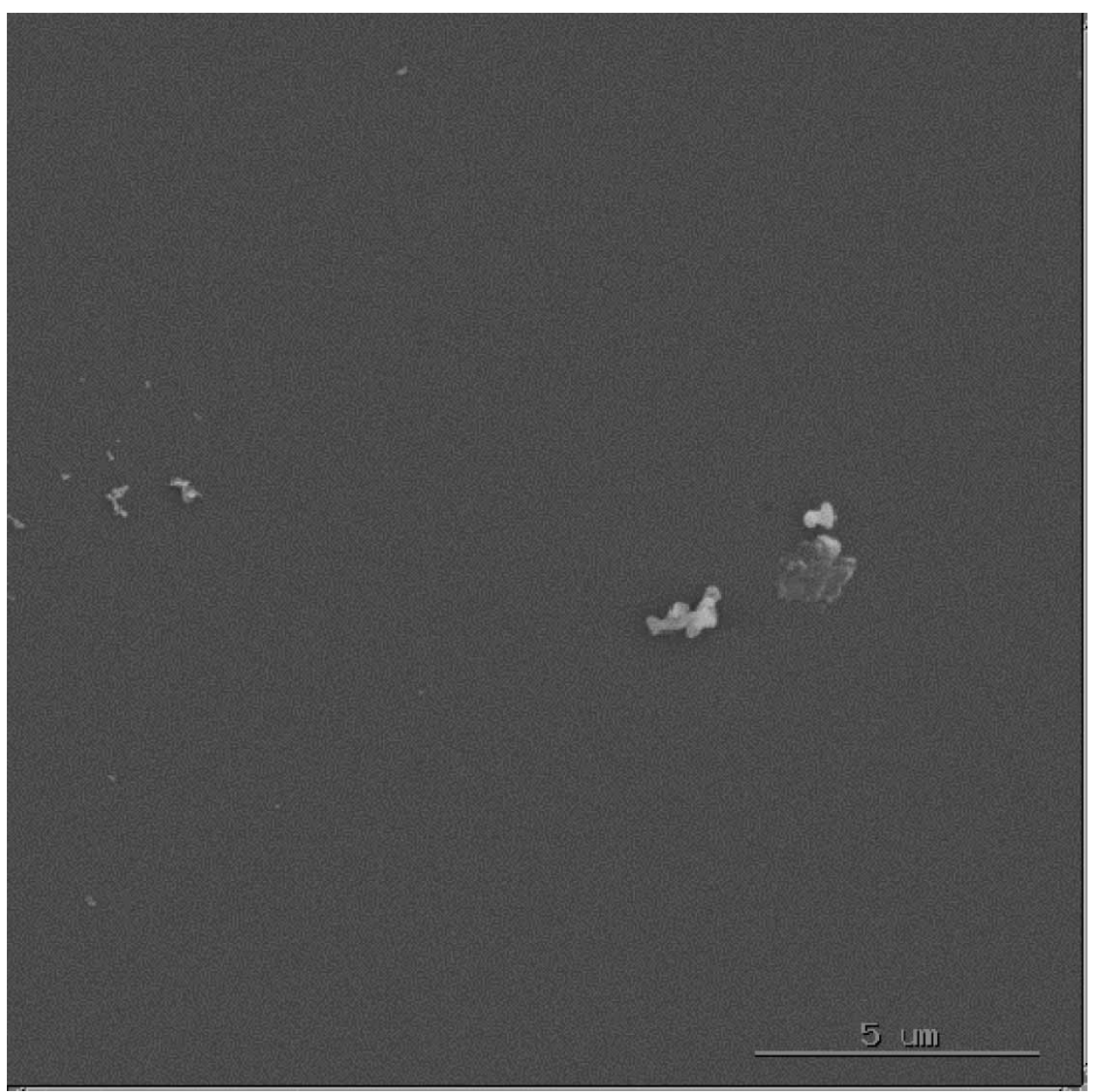

FIGURE 8 SEM for quenched sample of $n-S i$ from $400^{\circ} \mathrm{C}$ with scale of $5 \mu \mathrm{m}$.

for the slowly cooled sample from $600^{\circ} \mathrm{C}$ (Fig. 12). The surface of the slowly cooled sample is still far better than the untreated surface, as appears from Figure 13.

\subsubsection{E ffect of Rate of Cooling from Temperatures below $550^{\circ} \mathrm{C}$}

SEM results show that slowly cooled samples, from temperatures below $550^{\circ} \mathrm{C}$, have better surface quality than the quenched samples from the same temperature.

\subsubsection{Effect of Rate of Cooling from Temperatures above $550^{\circ} \mathrm{C}$}

A bove $550^{\circ} \mathrm{C}$ the quenched samples show better surface quality than the slowly cooled ones.

\subsection{Consistency Between Dark J -V Plot and SEM Data}

SEM results are consistent with J $-V$ plot results. In each case, annealing enhanced the $n-S i$ samples. Furthermore, the samples slowly cooled from $550^{\circ} \mathrm{C}$ or lower showed better J -V 


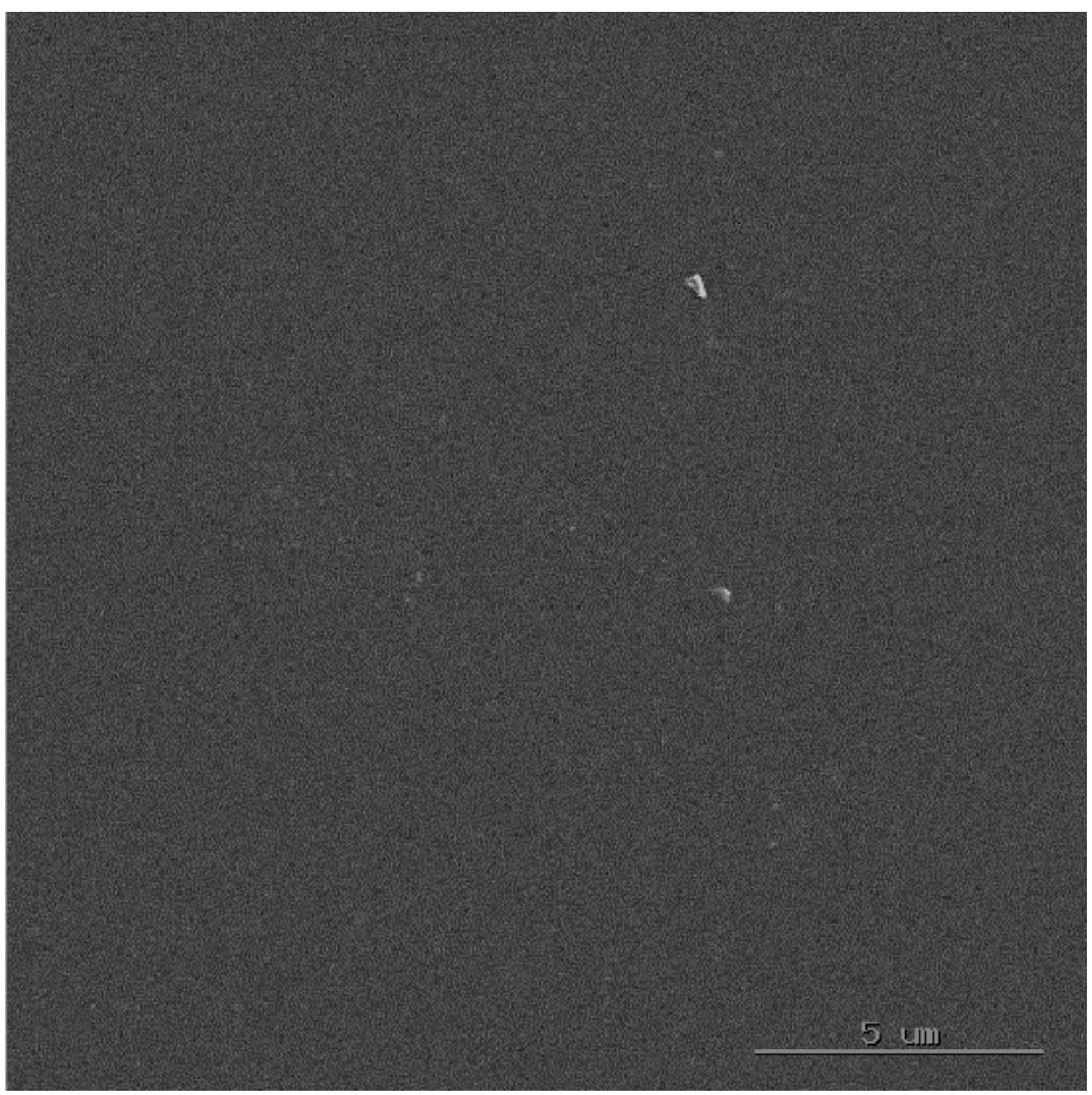

FIGURE 9 SEM for quenched sample of $n-S i$ from $600{ }^{\circ} \mathrm{C}$ with scale of $5 \mu \mathrm{m}$.

plots and better SEM results than their quenched counterparts. Samples quenched from temperatures above $550^{\circ} \mathrm{C}$ showed better J -V plots and SEM results than their slowly cooled counterparts.

\section{DISCUSSION}

The search for improved SC characteristics is an active area. Different literature techniques have been reported for this purpose. Coating with metallic thin layers has been reported [18]. Coating with other semiconducting materials is also known $[19,20]$. Electroactive material coating was reported [17]. Thin films of polymer coatings are also reported [21], in addition to many other techniques. In this paper, a simple technique is presented to improve crystallinity and $J-V$ plot quality of $n-S i$.

$M$ any valuable semiconductors have crystalline diamond or zinc-blend lattice structures. The crystallinity of these structures may be affected by various factors that cause 


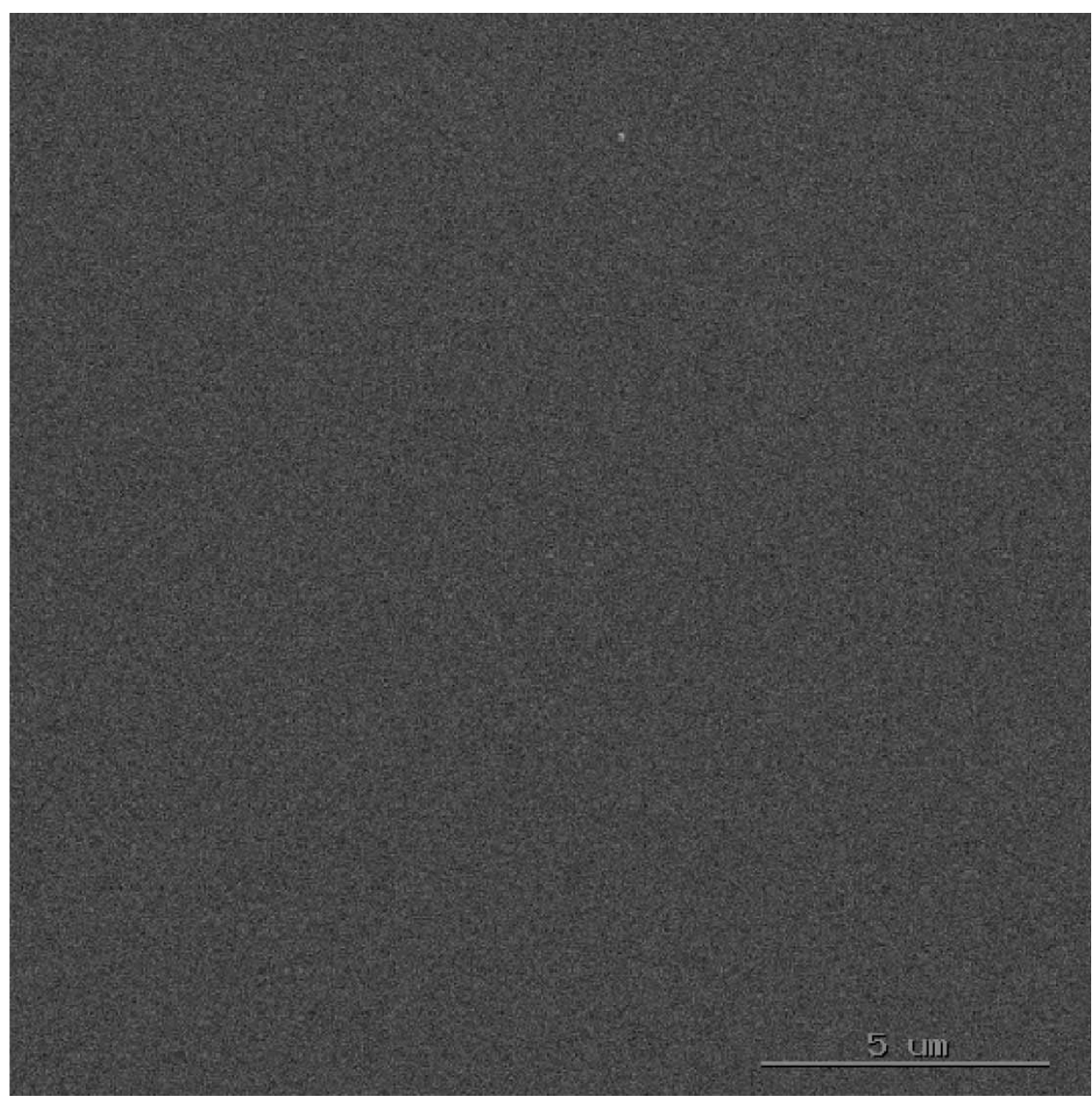

FIGURE 10 SEM for quenched sample of $\mathrm{n}$-Si from $700^{\circ} \mathrm{C}$ with scale of $5 \mu \mathrm{m}$.

defects [22]. In here, the enhancement effect of annealing and rate of cooling on $\mathrm{n}-\mathrm{Si}$ physical characteristics will be reasoned.

\subsection{Effect of Annealing}

A nnealing of semiconductor wafers enhances the crystal homogeneity, quality, performance and reliability. A nnealing also reduces defects, and lowers surface roughness. This has been reported in the literature.

It has been shown that photothermal processing can provide better performance and higher reliability of SC devices [3]. Fujioka et al. demonstrated that annealing SC in ultra-high vacuum chambers at about $700{ }^{\circ} \mathrm{C}$ effectively lowers the SC surface roughness [4]. Plane defects were lowered by annealing [5]. Thermal annealing plays an important role in the crystall lization process of homogeneous ultra-thin a-Si:H sub-layers [6]. Das et al. showed that, for thin films of $n-I n S e$, surface treatment such as etching and annealing leads to an increase in the efficiency of the PEC solar cells, at a pH value of 6.2 [1]. K itatani et al. [7] improved the crystal quality of highly strained GalnNAs/GaAs double quantum well structure, by developing a 


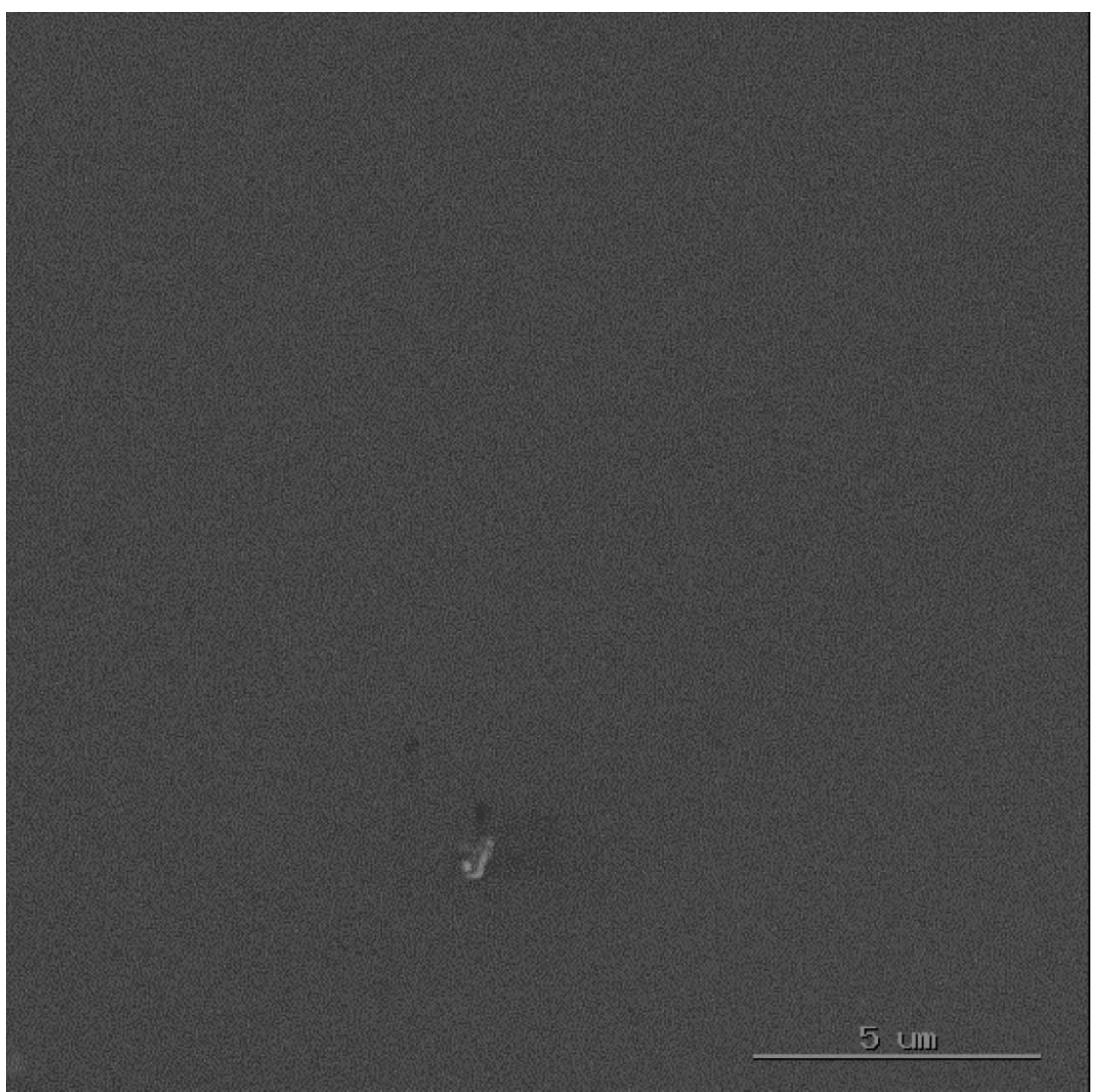

FIGURE 11 SEM for slowly cooled sample of $n-S i$ from $400^{\circ} \mathrm{C}$ with scale of $5 \mu \mathrm{m}$.

layer-by-layer annealing procedure. A Iso T. K itatani et al. [8] improved the optical properties of $\mathrm{G}$ al nNA s by thermal annealing. From these reports it is obvious that annealing SC improves the crystal structure, and would consequently improve the SC in PEC studies.

In this work, it was found that the anneal ed n-Si samples (at annealing temperatures in the range $400-700^{\circ} \mathrm{C}$ ) give better dark J $-V$ plots than their untreated counterparts. The improvement of dark J - $\mathrm{V}$ plots, obtained by annealing $\mathrm{n}-\mathrm{Si}$, can be explained as follows: annealing the $\mathrm{n}$-Si samples reduces the crystal defects, dislocation density, and surface roughness, and hence will improve the crystallinity, which will in turn improve the dark J-V plots. The annealed $n$-Si samples gave smoother dark J-V plots with better onset potential ( $\left.V_{\text {onset }}\right)$. The values of current densities for annealed samples were higher than those for untreated samples. This is consistent with literature reports [1, 3-8].

In this regard, one should explain why crystal defects and surface roughness inhibit dark current occurrence. With higher crystal disorder, especially at the surface, the surface states dominate. Such surface states would inhibit the majority carrier transfer across the SC/liquid interface [23]. Such inhibition will lower the dark current density. A nnealing reduces the surface state density by improving SC crystallinity, and therefore enhances dark current density. 


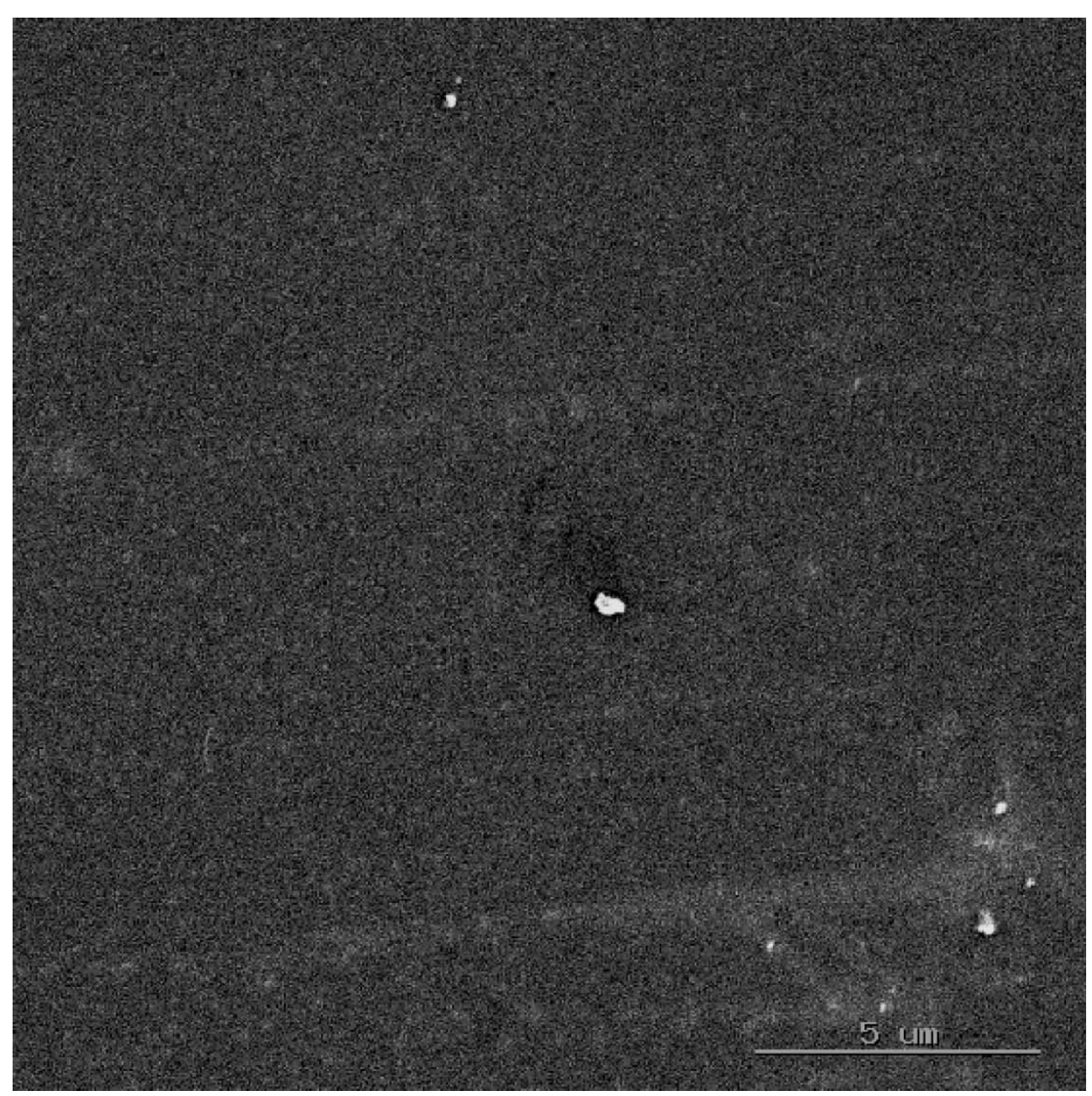

FIGURE 12 SEM for slowly cooled sample of $n$-Si from $600^{\circ} \mathrm{C}$ with scale of $5 \mu \mathrm{m}$.

In addition to lowering dislocation and defect densities, annealing may improve the SC properties by increasing the homogeneity in doping density distribution in the SC bulk because of maximizing randomness [24]. The enhancement of dark current density, observed by annealing $\mathrm{n}-\mathrm{Si}$ in this work, can therefore be understood.

Convincing evidence for this discussion comes from SEM results. The heated $n$-Si samples exhibit lower surface roughness than the unheated samples. This result supports the discussion that heating SC improves dark J -V plots by lowering surface state densities.

\subsection{Effect of Cooling R ate}

M any SC crystal parameters are affected by cooling rates. Examples of such parameters are: composition, uniformity, growth, film thickness, and luminescence properties. The dislocation density and concentration of structural defects also depend on the cooling rate of SC crystals. A uniform film growth of Si from $\mathrm{Cu}-\mathrm{Si}$ solution, with constant temperature gradient distribution, at the cooling rate of $0.1^{\circ} \mathrm{C} / \mathrm{s}$ and $0.05^{\circ} \mathrm{C} / \mathrm{s}$ (low cooling rate), was 


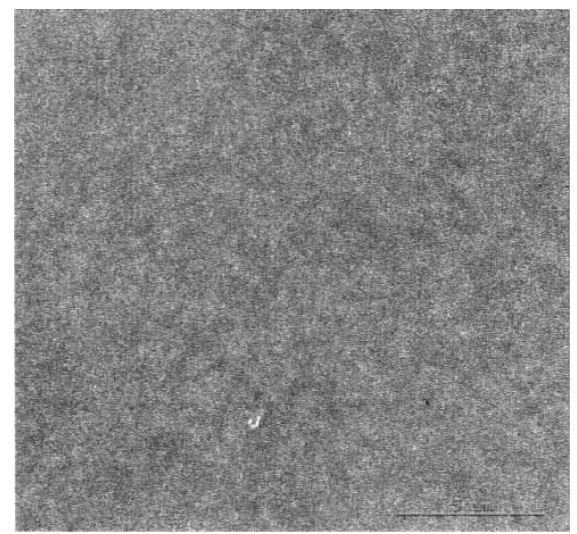

(a)

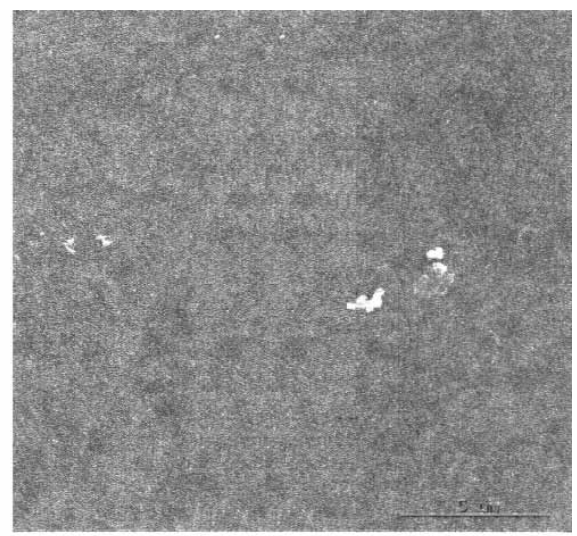

(b)

FIGURE 13 SEM results of (a) slowly cooled and (b) quenched n-Si sample from $400^{\circ} \mathrm{C}$ with scale of $5 \mu \mathrm{m}$.

possible [9]. Nishijima et al. [10] succeeded in obtaining an InGaA s crystal with a uniform composition in the growth direction by adjusting the cooling rate of the growth zone to be $0.2^{\circ} \mathrm{C} / \mathrm{h}$ (low cooling rate). Tachikawa and Mori [11] found that slow cooling of $\mathrm{InP} / \mathrm{Si}$ hetero-epitaxial crystals heated at $650^{\circ} \mathrm{C}$ reduces the dislocation density in the crystal. Sembian et al. [12] reported that slow cooling of SiGe, grown using liquid phase epitaxy onto Si, gave lower threading dislocation densities. They also found that with a slower cooling rate, the dislocation-assisted photoluminescence intensity was lowered, whereas the transverse optical phonon and the no-phonon photoluminescence intensity was higher. Kulakov et al. [13] reported that with higher cooling rates, higher surface phase shifts were observed in Si samples. These findings indicate that slow cooling improves SC crystallinity, lowers dislocation density, and enhances PEC efficiencies. The results obtained in this work are consistent with literature, as discussed here.

\subsubsection{Effect of Cooling from Temperatures Below $550^{\circ} \mathrm{C}$}

Literature reports [9-14] show that slow cooling of heated SC samples improved their crystallinity by affecting their dislocation density and structural defect concentration. Slow cooling also improves composition uniformity and luminescence properties. In this work, it is found that slowly cooled $\mathrm{n}$-Si samples, from temperatures below $550{ }^{\circ} \mathrm{C}$, had better dark $\mathrm{J}-\mathrm{V}$ plots than their quenched counterparts. Therefore the improvement of dark J-V plots of slowly cooled samples can be understood. The consistency with the literature reports is obvious.

The dark J-V plot of the untreated sample was not smooth, with high $\mathrm{V}_{\text {onset }}$ compared to other heated samples. This is presumably due to higher defect density in the untreated sample. Annealing the sample provides atoms with enough energy to overcome the forward energy barrier and to move from stable positions to new metastable positions. Therefore, annealing reduces the structural defect density in the crystal, and increases the dopant homogeneity. On cooling, metastable atoms tend to move back to their stable positions. Slow cooling of the crystal allows enough time for most metastable atoms of the heated sample to return to equilibrium positions at the storage temperature [2]. This in turn would minimize structural defects, presumably created during growth, and dislocations created during annealing. On the other hand, quenched samples may retain the atoms in their new metastable posi- 
tions after annealing. Quenching would deprive the metastable atoms from any pathways to return to their stable positions. The defect density in quenched samples will therefore be greater than their slowly cooled counterparts. In short, slow cooling reduces the surface state density. Such an effect improves SC composition, and therefore enhances dark current density.

Consistently with that, SEM results showed that the slowly cooled $\mathrm{n}$-Si sample from $400{ }^{\circ} \mathrm{C}$ exhibited lower surface roughness than its quenched counterpart. This result supports the discussion shown above.

\subsubsection{Effect of Cooling from Temperatures above $550^{\circ} \mathrm{C}$}

Increasing the annealing temperature results in removal of point defects, such as vacancies, and reduces the concentration of impurity interstitials at the surface. This is due to dopant diffusion in the SC bulk. When SC annealing is conducted at temperatures above $550^{\circ} \mathrm{C}$, for prolonged times, dislocations are formed, and the dopant concentration at the surface will be lowered [25]. Thus long-time annealing (slow cooling) of SC affects the sample crystallinity, which will in turn affect the SC surface roughness and its dark J-V plots. In this work, quenched $\mathrm{n}$-Si samples, from temperatures above $550^{\circ} \mathrm{C}$, had better dark J-V plots than their slowly cooled counterparts.

The dark J -V plot improvement of quenched samples can be explained. The quenched sample dark J-V plots are better than those of slowly cooled ones. This is due to high dislocation density in slowly cooled samples. Slow cooling of annealed n-Si samples allows longer exposure to higher temperatures. Diffusion of impurities will therefore increase. Such diffusion is represented by vacancy and interstitial diffusion, in addition to self diffusion of Si atoms. This in turn causes the formation of dislocations in addition to point-defects in slowly cooled samples. Thus exposure of n-Si to annealing temperatures above $550{ }^{\circ} \mathrm{C}$ for longer times would increase dislocation and point-defect densities. The presence of a high density of dislocation and point defects affects sample crystallinity. Consequently, the surface state density increases at the $\mathrm{SC}$ /liquid interface, and lowers the quality of dark J - V plots. On the other hand, quenching of annealed samples from temperatures above $550^{\circ} \mathrm{C}$ would prevent other diffusion mechanisms that may occur. Thus fewer dislocations or point-defects will be formed. In conclusion, quenching of $\mathrm{n}$-Si samples from temperatures above $550^{\circ} \mathrm{C}$ improves the $n-S i$ crystallinity, and consequently the dark J-V plots.

These discussions have direct supporting evidence from SEM. The n-Si sample, quenched from $600^{\circ} \mathrm{C}$, exhibits lower surface roughness than the slowly cooled counterparts. A s stated earlier, the lower roughness is an indicator of lower dislocations and lower point-defect densities.

Work is underway here to study the effects of the cooling rate on characteristics of other SC materials.

\section{CONCLUSIONS}

A nnealing $\mathrm{n}$-Si wafers enhances their characteristics at the solid/liquid interface in PEC experiments, as exhibited in dark J -V plot improvement. Slow cooling of annealed samples from $550^{\circ} \mathrm{C}$ or lower further enhances PEC characteristics. With higher annealing temperatures, quenching gives better results than slow cooling. SEM results confirmed all PEC study results. It is therefore possible to enhance semiconductor characteristics at the solid/liquid interface in addition to their surface characteristics by controlling annealing temperatures and rates of cooling. 


\section{Acknowledgements}

The authors wish to acknowledge help from the scanning electron microscopy facility at ICMCB, University of Bordeaux, France. Technical assistance from colleagues at A n-Najah N. University is acknowledged. Helpful discussions from Dr. Ayman Daoud and Dr. M osa Hasan are also appreciated. A ssistantships from EGIDE offices, France, are also acknowledged.

\section{References}

[1] Das, V. D., Sathyanarayanan, J. and Damodare, L. (1997). Effect of annealing and surface treatment on the efficiency of photoelectrochemical (PEC) solar cells with vacuum-deposited n-InSe thin film electrode. Surf. Coat. Technol., 94-95, 669-671.

[2] Van V lack, L. H. (1970). M aterial Science for Engineers. A ddison-Wesley Publishing Company, Inc., Reading, pp. 105-107.

[3] Singh, R., Fakhruddin, M. and Poole, K. F. (2000). Rapid photothermal processing as a semiconductor manufacturing technology for 21st Century. Applied Surface Science, 168, 198-203.

[4] Fujioka, H., Ohta, J., Katada, H., Ikida, T., Noguchi, Y. and Oshima, M. (2001). Epitaxial growth of semiconductor on $\mathrm{SrTiO}_{3}$ substrates. J. Crystal Growth, 229, 137-141.

[5] Claverie, A., Colombeau, B., A ssayag, G. B., Bonafos, C., Cristiano, F., Omri, M. and M auduit, B. (2000). Thermal evolution of extended defects in implanted $\mathrm{Si}$ : Impact on dopant diffusion. Material science in Semiconductor Processing, 3, 269-277.

[6] Wang, L., Huang, X., M a, Z., Li, Z., Shi, J., Zhang, L., Bao, Y., Wang, X., Li, W., X u, J. and Chen, K. (2001). Thermal annealing of a-Si:H/a-SiN $: H$ multilayers. Appl. Phys. A.

[7] Kitatani, T., Kondow, M. and Tanaka, T. (2000). Effect of thermal annealing procedure and a strained intermediate layer on a highly-strained GalnNAs/GaAs double-quantum-well structure. J. Crystal Growth, 221, 491-495.

[8] K itatani, T., Nakahara, K., Kondow, M., Uomi, K. and Tanaka, T. (2000). M echanism analysis of improved GalnNA s optical properties through thermal annealing. J. Crystal Growth, 209, 345-349.

[9] Kita, K., Wen, C., Otomo, J., Yamada, K., K omiyama, H. and Takahashi, H. (2002). Study on the lateral growth of silicon films from metal solutions with temperature gradient. J. Crystal Growth, 234, 153-158.

[10] Nishijima, Y., Makajima, K., Ostubo, K. and Ishikama, H. (2000). InGaAs single crystal with a uniform composition in the growth direction grown on an InGaA s seed using the multicomponent zone growth method. J. Crystal Growth, 208, 171-178.

[11] Tachikawa, M. and M ori, H. (1998). Reduction of dislocation generation for heteroepitaxial III-V/Si by slow cooling. J. Crystal Growth, 183, 89-94.

[12] Sembian, A. M., B anhart, F., K onuma, M., Weber, J., Babu, S. M. and Ramasamy, P. (2000). Influence of cooling rate on the dislocation and related luminescence in LPE SiGe layers grown on Si (100) substrates. Thin Solid Films, 372, 1-5.

[13] Kulakov, M. A., Hoster, H., Zhang, Z. and Bullemer, B. (1997). Cooling rate determination of Si samples in a radiative quench and observation of an apparent temperature shift of the $1 \times 1-7 \times 7$ surface phase transition. Surface Science, 376, L 414-L 418.

[14] Lee, M. K., Tseng, Y. C. and Chu, C. H. (1998). A high-gain porous silicon metal-semiconductor-metal photodetector through rapid thermal oxidation and rapid thermal annealing. Appl. Phys. A, 67, 541-543.

[15] Hilal, H., Turner, J. and Frank, A. Tailoring the energetics and kinetics of interfacial charge transfer at the semiconductor/liquid junction: Chemically modified n-GaAs, unpublished observations.

[16] Mao, D., K im, K. and Frank, A. J. (1994). Open-circuit photovoltage and charge recombination at semiconductor/liquid interfaces. J. Electrochem. Soc., 141, 1231-1236.

[17] Hilal, H. S., Shakhshir, S. and M asoud, M. M. (2002). J. Electronal Chem., 527, 47.

[18] Fan, R., Keil, G. and Bard, A. J. (1983). J. Am. Chem. Soc., 105, 220.

[19] Bergene (1995). Trapping of minority charge at irradiated semiconductor/electrolyte heterojunctions. Int. J. Hydrogen Energy, 20, 785-788.

[20] B adawy, W. A. (2002). Improved n-Si/oxide junctions for environmentally safe solar energy conversion. Solar Energy Materials \& Solar Cells, 71, 281-294.

[21] Lewis, N. S. (2001). Frontier of research in electrochemical solar energy conversion. J. Electroanal. Chem., $508,1-10$.

[22] Sze, S. M . (1981). Physics of Semiconductor Devices. John Wiley \& Sons, Inc., New York, pp. 8-9.

[23] Finklea, H. O. (Ed.) (1988). Semiconductor Electrodes. Elsevier, A msterdam, pp.32-38.

[24] Streetman, B. G. (1980). Solid State Electronic Device, 2nd ed. Prentice-Hall, Inc. Englewood Cliffs, N.J., pp. 133-136.

[25] Seidel, T. E. (1983). In: Sze, S. M. (Ed.), VLSI Technology. McGraw-Hill Book Company, New York, pp. 242-244. 

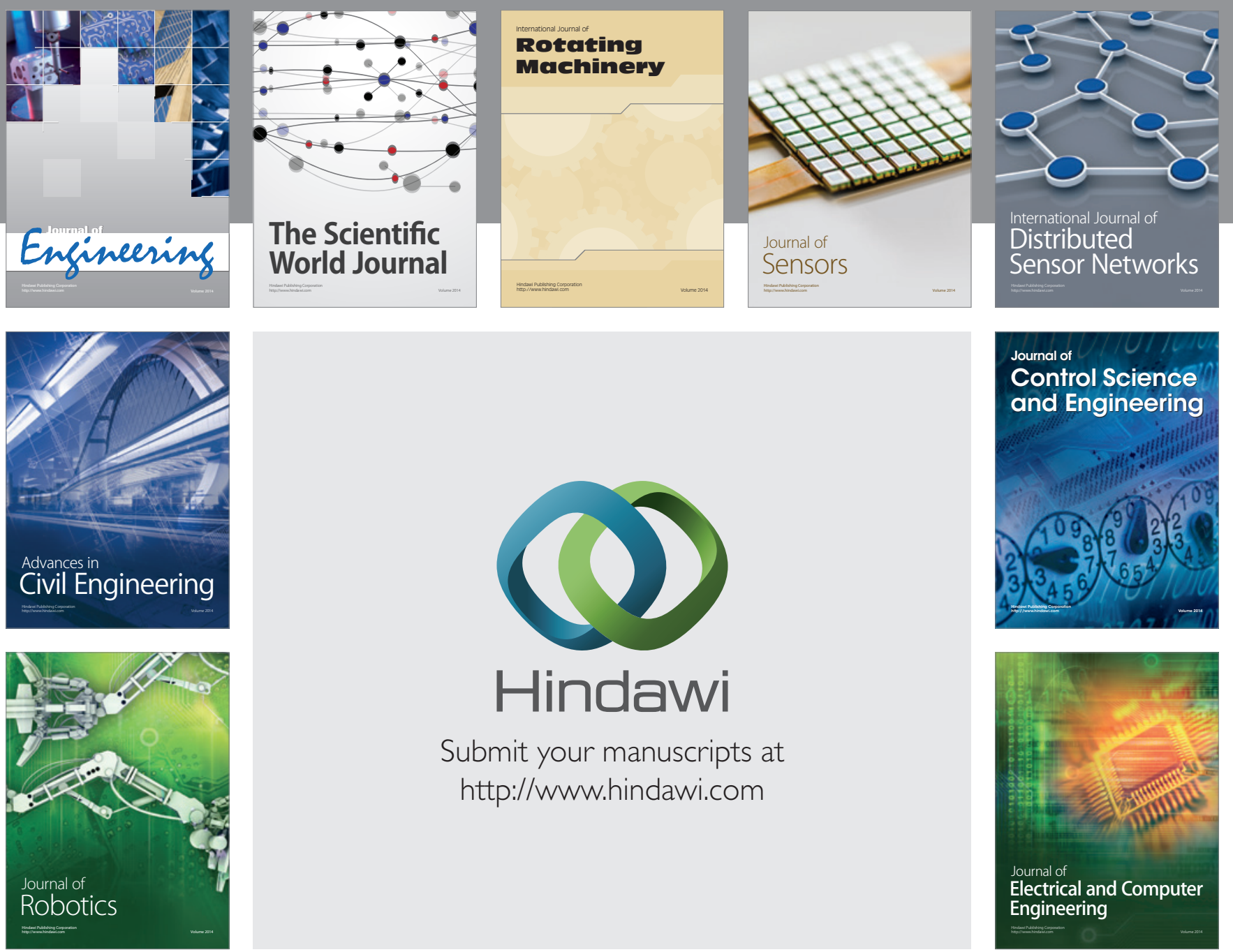

Submit your manuscripts at

http://www.hindawi.com
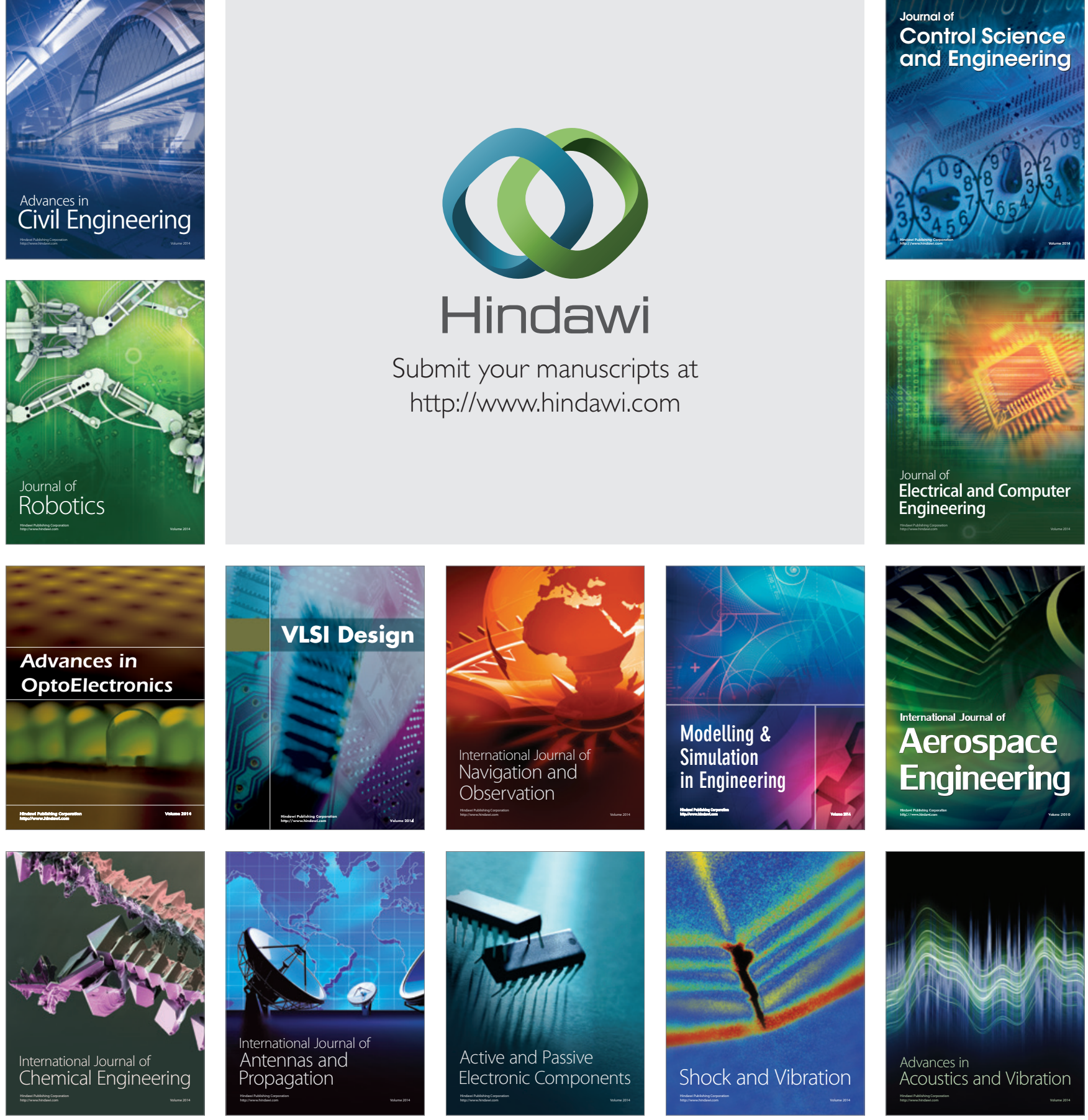